ISSN 1518-3483

Licenciado sob uma Licença Creative Commons

(c) (1)

\title{
Professores alfabetizadores: estudo sobre elementos do desenvolvimento profissional
}

\author{
Literacy teachers: study on elements of \\ professional development
}

\begin{abstract}
Alfabetizadores: estudio sobre los elementos de desarrollo profesional
\end{abstract}

\section{Liliamar Hoça ${ }^{[a]}$ Joana Paulin Romanowski ${ }^{[a]}$, Simone Regina Manosso Cartaxo ${ }^{[b]^{*}}$}

[a] Pontifícia Universidade Católica do Paraná (PUCPR), Curitiba, PR, Brasil

[b] Universidade Estadual de Ponta Grossa (UEPG), Ponta Grossa, PR, Brasil

\section{Resumo}

O texto tem o propósito de indicar os elementos que caracterizam o desenvolvimento profissional dos professores alfabetizadores. Focaliza a análise sobre tempos e espaços de vida profissional e pessoal desses professores, considerando acontecimentos e

\footnotetext{
LH: Doutoranda em Educação, e-mail: liliamarh@up.edu.br JPR: Doutora em Educação, e-mail: joana.romanowski@pucpr.br SRMC: Doutora em Educação, e-mail: simonemcartaxo@hotmail.com
} 
aprendizagens, necessidades e expectativas, ao longo da carreira. A metodologia de estudo é de abordagem qualitativa, considerando como fonte de dados os depoimentos de professores alfabetizadores de um município da região metropolitana de Curitiba. Para a análise foram observados os momentos e acontecimentos "charneira" (JOSSO, 2004), a partir do que dizem os professores alfabetizadores sobre a inserção profissional e continuidade como alfabetizadoras. O estudo aponta o ingresso como professor alfabetizador, a formação durante a prática pedagógica, a formação continuada e as condições de trabalho como elementos, momentos e espaços fundamentais na constituição do desenvolvimento profissional. Os resultados, ainda, indicam que o desenvolvimento profissional nasce, em um primeiro momento das incertezas, e se intensifica com a estabilidade na prática alfabetizadora, favorecendo a continuidade para tornar-se professor alfabetizador.

Palavras-chave: Desenvolvimento profissional. Professores alfabetizadores. Inserção profissional.

\section{Abstract}

The text aims to indicate the characteristics of professional development of literacy teachers. The study focuses on the analysis of time and space for professional and personal lives of these teachers, considering events and learning, needs and expectations throughout his career. The research methodology is qualitative approach, considering as a data source the literacy teachers testimonials of the metropolitan region of Curitiba. For the analysis times and events "charneira" were observed (JOSSO, 2004), from what say the literacy teachers on professional insertion and continuity as literacy teachers. The study points out the ticket as a teacher literacy, learning for pedagogical practice, continuing education and working conditions as elements, moments and key areas in the constitution of professional development. The results also indicate that the professional career development born at first based on the uncertainties, and then it intensifies within stability in literacy practice, favoring continuity to become teacher literacy.

Keywords: Professional development. Literacy teachers. Professional insertion.

\section{Resumen}

El texto tiene por objeto indicar las características del desarrollo profesional de los maestros de alfabetización. Se centra en el análisis del tiempo y el espacio para la vida profesional 
y personal de estos maestros, teniendo en cuenta los acontecimientos y el aprendizaje, las necesidades y expectativas a lo largo de su carrera. La metodología de estudio es un enfoque cualitativo, teniendo como fuente de datos los testimonios de maestros alfabetizadores de la región metropolitana de Curitiba. Se observó en el análisis de los eventos y los tiempos "charneira" (JOSSO, 2004), a partir de lo que dicen los maestros de alfabetización en la inserción profesional y la continuidad como alfabetizadores. El estudio señala la entrada como la alfabetización de profesores, la formación en la práctica pedagógica, la formación continua y las condiciones de trabajo como elementos, los momentos y las áreas clave en la constitución de desarrollo profesional. Los resultados también indican el desarrollo profesional proviene de las incertidumbres primeros momentos y se intensifica con la estabilidad de la práctica de la alfabetización, favoreciendo la continuidad de convertirse en maestro de alfabetización.

Palabras clave: Desarrollo profesional. Alfabetizadores. La inserción profesional.

\section{Introdução}

O desenvolvimento profissional dos professores é um tema apontado como integrante do campo de investigações sobre formação docente. As reflexões sobre desenvolvimento profissional dos professores se intensificaram a partir da década de 1970 e do final da década 1980, em estudos produzidos nos Estados Unidos, ao associarem o desenvolvimento profissional como possibilidade de melhoria do ensino e da aprendizagem na escola (DESIMONE, 2009).

No continente europeu, por exemplo, a Espanha, desde 1984, o desenvolvimento profissional tem sido realizado em Centros do Professorado, com uma variedade de modalidades de formação profissional, como indicam Vaillant e Marcelo (2012, p. 190); no Reino Unido, nos anos de 1990, muitos programas de desenvolvimento profissional foram organizados durante a implantação do Currículo Nacional, na perspectiva 
da "pedagogia de resultados" (CAMPBELL, 2007); em Portugal, a intensificação das preocupações com o desenvolvimento profissional docente é mais recentes com a chamada "Estratégia de Lisboa"1, fortalecendo a formação de professores (CANÁRIO, 2007). No Brasil, os debates em torno do desenvolvimento profissional são recentes ${ }^{2}$ e, de modo geral, estão associados à formação continuada dos professores.

A abordagem do desenvolvimento profissional dos professores tem assumido a predominância sobre a compreensão dos professores como profissionais, considerando a prática docente e o aprimoramento profissional. Estão associados ao desenvolvimento profissional a formação permanente, continuada, em serviço, aprendizagem ao longo da vida (VAILLANT; MARCELO, 2012, p. 167).

O estudo focalizado neste texto abrange discussões sobre as experiências de aprendizagem ao longo da carreira, o conhecimento, as habilidades, o ensino, a formação inicial e continuada, as expectativas e necessidades de professores alfabetizadores. Neste sentido, as categorias consideram momentos e acontecimentos "charneira" (JOSSO, 2004), a partir do que dizem os professores alfabetizadores sobre a inserção e continuidade como alfabetizadoras.

O estudo foi realizado com professores alfabetizadores de um município da região metropolitana de Curitiba, envolvendo depoimentos escritos por meio de roteiro com questões direcionadas aos alfabetizadores. A análise dos depoimentos considerou o conteúdo das respostas e foi feita com base interpretativa em Bardin (2007), a partir da leitura flutuante, seguida do apontamento de indicadores, classificação e categorização,

1 “Orientações que enfatizam o papel chave da qualificação de recursos humanos, no Contexto das políticas de 'Aprendizagem ao Longo da Vida' e, nesse contexto, o papel decisivo a desempenhar pelos professores, no sentido de serem concretizáveis as ambiciosas metas educativas" (CANÁRIO, 2007, p. 133).

2 Um dos primeiros artigos publicados discute a relação entre avaliação docente e seus efeitos no desenvolvimento profissional na perspectiva de uma pedagogia de resultados (COSTA, 2007); e na perspectiva da relação entre formação continuada e desenvolvimento profissional, ver Romanowski e Martins (2010). 
considerando as unidades de registro, para as possíveis interpretações, cotejando com os referenciais que orientam as análises.

Para compreender o que dizem os professores alfabetizadores sobre suas aprendizagens e expectativas, o estudo considerou necessário entender que a alfabetização no Brasil tem uma trajetória marcada pela complexidade, originada em fatores sócio históricos, pedagógicos e políticos educacionais que, ao longo do tempo, foram marcando esse processo. As políticas públicas no Brasil direcionadas à alfabetização enfatizam a garantia do acesso à educação, à permanência e sucesso dos alunos, à concepção de leitura e escrita, à prática em sala de aula, metodologia, avaliação, recursos, formação de professores alfabetizadores e à carreira docente. Na dinâmica processual, esses elementos se interligam, originando o ethos alfabetizador.

Por ethos alfabetizador entende-se o conjunto de hábitos, crenças e valores, elaborados por um grupo ao longo do tempo, a partir de determinados condicionantes históricos, sociais, políticos e econômicos que se encontram inter-relacionados, sendo estes determinantes destacados no trabalho de Mortatti (2000).

Em relação ao tema desenvolvimento profissional dos professores, um dos primeiros estudos foi realizado por Huberman no ano de 1989, em Genebra. Tal estudo apontou para o ciclo de desenvolvimento marcado por forças mobilizadoras advindas das expectativas sociais, atividades realizadas, papéis desempenhados no interior da escola, reconhecimento e organização do trabalho. Os aportes teóricos do estudo tomam por referência Marcelo (1999, 2009); Day (2001) apresenta reflexões sobre o "saber fazer" do professor, a profissão, o espaço da escola, o percurso de formação continuada e os processos que compõem desenvolvimento profissional; Tardif (2010) que concebe os saberes dos professores como advindos da prática e experiências profissionais.

Portanto, este artigo expressa o resultado da pesquisa desenvolvida, com o objetivo de analisar desenvolvimento profissional de professores alfabetizadores, considerando os acontecimentos e aprendizagens ao longo da carreira como elementos constituintes do processo de 
desenvolvimento profissional para compreender o que constitui o tornar-se professor alfabetizador.

\section{Desenvolvimento profissional dos professores na perspectiva do aprendizado profissional}

O tema do desenvolvimento profissional dos professores tem sido tratado sob vários enfoques, os processos de formação ao longo da carreira docente (VAILANT; MARCELO, 2012; ROMANOWSKI; MARTINS, 2010); os efeitos do desenvolvimento sobre os professores (DESIMONE, 2009); reforma educacional e o desenvolvimento docente (CAMPBELL, 2007; CANÁRIO, 2007); uma reflexão que ocorre no sentido de compreender a profissão docente e a pessoa do professor (JOSSO, 2004; DAY, 2001). Neste artigo, focalizamos a aprendizagem do professor enquanto profissional e pessoa, considerando elementos como experiências de trabalho, experiências cognitivas e emocionais, histórias de vida, fase da carreira, contextos sociais e políticos da profissão, liderança e apoio de outros professores, oportunidades de diálogo e reflexão sobre a prática (DAY, 2001).

Analisar desenvolvimento profissional é se voltar à aprendizagem dos adultos, considerando que, no caso dos professores, ela poderá receber influências de inúmeros fatores, conforme pesquisa de Day (2001, p. 313-314):

[...] experiências de trabalho, histórias de vida, fases da carreira, condições e contextos sociais e políticos, culturas da escola, liderança e apoio de pares, oportunidades para a reflexão, diálogo autêntico entre o indivíduo e o sistema, a qualidade das experiências de aprendizagem, a relevância da experiência de aprendizagem face as necessidades intelectuais e emocionais, a sua confiança na participação em práticas de identificação das necessidades e dos seus contextos, a assunção da sua aprendizagem. 
Esse conjunto de acontecimentos que se entrelaçam, construído ao longo do percurso profissional do professor, expressa vários tipos de aprendizagens: algumas ocorrendo de forma deliberada, outras planejadas e, também, existirão aquelas altamente estruturadas, que necessitarão do apoio de orientadores, dos próprios pares ou de colegas mais experientes. De acordo com Day (2001), essas aprendizagens aos serem registradas, sistematizadas e revistas pelos professores, podem contribuir para a continuidade do desenvolvimento profissional docente.

Na perspectiva apresentada pelo autor, todas as experiências de aprendizagem do professor favorecem de alguma maneira os processos nas salas de aula, nas escolas, nas relações interpessoais com alunos e com demais profissionais.

Para Marcelo (2009), o processo de desenvolvimento profissional dos professores apresenta como características importantes:

a) A apropriação dos conhecimentos da docência não ocorre no modelo transmissivo, mas na concepção de que o professor deve observar, analisar e avaliar para transformar as tarefas de ensino.

b) É um processo que acontece a longo prazo.

c) Ocorre em contextos reais de trabalho, com seus avanços e dificuldades, considerando os conhecimentos prévios dos integrantes.

d) Está relacionado à escola enquanto contexto que permite seus integrantes agirem de forma participativa, crítica e voltados para as mudanças.

e) Os professores estão em constante avanço, pois a partir da reflexão sobre as experiências, eles podem reelaborar práticas pedagógicas e reconsiderar aspectos teóricos que possam ter sido mal interpretados.

f) Pode parecer que se trata de um processo individualizado, mas é colaborativo.

g) Não existe um modelo único que deve ser implantado. Há inúmeras possibilidades de organizar esse processo, contando com a participação dos professores. 
Segundo Marcelo (2009), o desenvolvimento profissional dos professores é um processo que se estrutura no plano individual e coletivo, composto pelas experiências da prática pedagógica, da formação e dos eventos profissionais que participam em determinados tempos. $\mathrm{O}$ autor destaca que a identidade profissional configura o processo de desenvolvimento profissional. Segundo ele, essa identidade não é dada, mas desenvolvida no percurso da profissão, considerando as relações estabelecidas no contexto de trabalho. É um olhar para a própria atividade realizada em diferentes momentos, interpretando e reinterpretando as experiências profissionais e pessoais que, de algum modo, interferem no trabalho do professor.

Quando se fala de desenvolvimento profissional dos professores, discute-se um conjunto de elementos que provocam mudanças nos conhecimentos e atitudes da ação docente, como explica Marcelo (2009). Os conhecimentos e atitudes são colocados em três níveis: conhecimentos para a prática são aqueles que servem para organizar e compreender o ensino, derivados da investigação universitária; conhecimentos na prática são adquiridos na ação - como tomada de decisões e juízos para resolver determinadas situações - e precisam da reflexão; por fim, os conhecimentos da prática são aqueles que envolvem o engajamento em projetos de desenvolvimento da escola, da formação e da comunidade, com as reflexões feitas pelo grupo de professores de uma determinada escola e que constituem um movimento próprio desse espaço.

Buscar compreender o desenvolvimento profissional dos professores é uma imersão em um vasto campo de relações de formação, trabalho e experiências pessoais, no qual os professores são atores contextualizados historicamente e socialmente, que aprendem ao longo da vida e da profissão, transformando os conhecimentos em práticas consideradas apropriadas para o aprendizado de seus alunos. 


\section{Contexto da alfabetização e implicações para o desenvolvimento profissional do professor alfabetizador}

Neste trabalho, apresentamos um recorte das discussões sobre o processo de Alfabetização no Brasil, considerando o ethos alfabetizador, constituído pelas questões históricas e sociais da educação que intervêm nesse processo. Partindo da ideia que o desenvolvimento profissional dos professores está relacionado a um conjunto de elementos que provocam mudanças nos conhecimentos e atitudes da ação docente (MARCELO, 2009) identificamos que o desenvolvimento profissional do alfabetizador está associado a alguns conhecimentos construídos historicamente: as disputas históricas e hegemônicas sobre os métodos de alfabetização, as mudanças paradigmáticas no campo da alfabetização e a construção do conceito de alfabetização e letramento.

As questões históricas que marcaram a alfabetização têm início com a criação dos sistemas de escrita e as formas como os povos foram se apropriando deles. A formalização do ensino das letras configurou-se de formas diferenciadas, de acordo com as necessidades e intenções. Entre os gregos, com as escolas do alfabeto, aprender a ler e escrever tornou-se uma tarefa de alcance popular. Na Idade Média, aprender a ler e escrever era de acesso a poucos e não era uma atividade prioritariamente escolar. Com a Revolução Francesa, a escola pública e laica difunde-se conduzida pelo ideário iluminista, e a alfabetização é introduzida como matéria escolar para atender famílias burguesas que, na condição então revolucionária, priorizavam acesso a conhecimentos científicos, vida cultural e consolidação do sentimento de pertencimento a uma nação.

A partir da Revolução Industrial, a alfabetização funciona como instrumento de disciplina e ordem para preparar mão de obra especializada. Com o capitalismo, são definidos novos conteúdos da alfabetização, pois o modo de produção é alterado, exigindo-se um mínimo de instrução do trabalhador como condição básica para o processo de modernização das sociedades. 
No Brasil, a preocupação com a escolarização da população (especificamente, com o ensino da leitura e da escrita) só passou a ser uma repercussão política ao final do período imperial (1878-1881), quando os analfabetos foram proibidos de votar e os governantes perceberam que uma massiva parte da população não tinha conhecimentos mínimos sobre a escrita. Será em 1981, com a Primeira Constituição Republicana do Brasil, que entra em pauta a questão de alfabetização do povo brasileiro com a definição de quem podia votar: sexo masculino, saber ler e escrever ou mesmo só assinar o nome. Assim, redefine-se o status de cidadania, alterando o significado de escolarização e função social da alfabetização.

As disputas históricas e hegemônicas sobre os métodos de alfabetização que foram se constituindo são explicadas por Mortatti (2000). Ela explica que, no período da República, com as reformas na instrução pública, o ensino da leitura e da escrita passou a ser escolarizado com práticas organizadas de forma metódica, sistemática e com intencionalidade.

Mortatti (2000) apresenta quatro momentos compreendendo o período de 1876 a 1994, os quais demonstraram a existência de fases marcadas pela predominância de métodos e concepções, com interesses de âmbito político e social, que alicerçavam o discurso da modernidade pedagógica.

O primeiro momento, entre 1876 a 1890, que abrange o final do período imperial e o início da República, caracterizado pelo enfretamento de ideias entre defensores dos métodos sintéticos e novo método da palavração; o segundo momento, ocorreu entre 1890 e 1920, com o debate entre partidários da utilização dos métodos analíticos e sintéticos; o terceiro período, de 1920 ao final de 1970, foi marcado pelas ideologias de defensores dos métodos analíticos e sintéticos e aqueles que propunham a verificação da maturidade das crianças para alfabetização, por meio dos testes ABC de Lourenço Filho em 1969, com posterior introdução dos anos 80 , o estudo realizado pelas pesquisadoras Ferreiro e Teberosky chegou ao método misto. E o quarto momento foi dado pela autora, no período de 1980 a 1994, pelo enfrentamento entre os partidários da perspectiva construtivista e os defensores dos antigos métodos. Para Soares (2004), 
vivenciamos mudanças paradigmáticas que marcaram os diferentes momentos da alfabetização: um paradigma behaviorista, dominante nas décadas de 1960 e 1970, substituído, na década de 1980, por um paradigma cognitivista, o qual avançou na década de 1990, para um paradigma sociocultural. Para a autora, a transição da teoria behaviorista para a teoria cognitivista representou uma mudança radical de paradigma e a transição da teoria cognitivista para a perspectiva sociocultural se constitui antes como um aprimoramento do paradigma cognitivista do que propriamente como uma mudança paradigmática.

No Brasil, essas mudanças ocasionaram inúmeras discussões sobre a prática da alfabetização, resultando em mudanças metodológicas do processo de alfabetização até então desenvolvido nas escolas.

Os estudos desenvolvidos por Ferreiro e Teberosky buscaram explicar a psicogênese da língua escrita, que leva a entender como uma criança aprende a ler e escrever, considerando-a um sujeito ativo, questionando a "[...] centralidade do ensino e em decorrência, dos métodos e cartilhas de alfabetização quanto nos resultados dos testes de maturidade para o aprendizado da leitura e escrita" (MORTATTI, 2000, p. 330).

Nas secretarias de educação dos estados e municípios e com a ajuda das universidades em outros lugares, as discussões passaram a abordar a autonomia didática em contraponto a perspectiva tecnicista. Com isso, foram rejeitadas as chamadas receitas didático-pedagógicas para investir na formação de um professor com conhecimento sobre o processo de aprendizagem das crianças e que conciliasse competência técnica com o compromisso político de uma educação democrática e de qualidade (MORTATTI, 2000).

A revisão metodológica transferiu o eixo de discussão do como ensinar e do uso dos métodos para a aprendizagem do sujeito ativo, enfatizando a centralidade do aluno na construção do conhecimento e o papel do professor, que passa a ser considerado um mediador do processo. Segundo Gontijo (2014, p. 17), "[...] apesar da existência de críticas ao seu caráter biopsicologizante, esse modelo continua na base das orientações do Ministério da Educação (MEC) para o ensino da escrita”. 
Outro elemento que vem fazer parte do percurso da alfabetização no Brasil é o conceito de letramento, introduzido pelos estudiosos do campo da linguística na década de 90, como informa Gontijo (2008).

O letramento não pode ser confundido com um método de alfabetização e também não é um termo substituto. Trata-se de uma análise aprofundada sobre as práticas de escrita que acompanham o desenvolvimento da sociedade, ocasionando mudanças cognitivas, políticas, sociais e econômicas, como explica Kleiman (1995). O foco da discussão reside nas práticas sociais de leitura e escrita, nas quais as pessoas estão inseridas, à medida que o analfabetismo vai sendo superado. Não bastava estar apenas alfabetizado, era necessário fazer uso dessas práticas em diferentes contextos e a partir de diferentes instrumentos. Como afirma Soares (1998), estudiosa do letramento e suas práticas no Brasil:

As pessoas se alfabetizam, aprendem a ler e a escrever, mas não necessariamente incorporam a prática da leitura e da escrita, não necessariamente adquirem competência para usar a leitura e a escrita, para envolver-se com as práticas sociais de escrita: não leem livros, jornais, revistas [...] sentem dificuldade para escrever [...] sentem dificuldade em encontrar informações num catálogo telefônico, num contrato de trabalho, numa conta de luz, numa bula de remédio (SOARES, 1998, p. 45-46).

As práticas de leitura e escrita desenvolvidas na escola nem sempre tomaram como pressupostos as práticas sociais, decorre então a necessidade da revisão dos encaminhamentos das práticas e da formação dos professores. As ponderações de Paulo Freire marcam fortemente essas revisões.

As ideias decorrentes dos conceitos de alfabetização, não apenas como um processo de codificação e decodificação e do letramento, proporcionaram a inserção da prática de "alfabetizar letrando". A proposta de "alfabetizar letrando" toma como base as ideias de Soares (1998) que destaca que alfabetizar e letrar são duas ações com distinções, mas que na prática devem acontecer de forma indissociável, isto é: "[...] ensinar a ler e escrever no contexto das práticas sociais da leitura e da escrita, de modo que o indivíduo se tornasse, ao mesmo tempo, alfabetizado e 
letrado" (SOARES, 1998, p. 47). Atualmente, as discussões sobre "alfabetizar letrando" são evidenciadas nos documentos redigidos para a formação de professores alfabetizadores, organizados pelo MEC na ação do Pacto Nacional de Alfabetização na Idade Certa (2012).

Assim, ao apresentar o ethos alfabetizador, constituído pelas questões históricas e sociais da educação, consideramos que a formação do professor alfabetizador foi se configurando de forma diferenciada para atender às necessidades de cada momento histórico. Hoje, por intermédio dos estudos realizados, conseguimos reunir elementos para investigarmos o desenvolvimento profissional do alfabetizador situando-o historicamente.

\section{O processo do levantamento}

O estudo realizado está apoiado na abordagem qualitativa de pesquisa, que, de acordo com Bogdan e Biklen (1994), se configuram a partir da coleta de dados no ambiente natural, com dados descritivos, repletos de descrições sobre os sujeitos participantes, o contexto, o ambiente e os acontecimentos.

Trata-se de um estudo realizado em escolas públicas municipais de uma cidade da Região Metropolitana de Curitiba, de abril a junho de 2015, com a coleta de dados realizada por meio de um roteiro estruturado entregue para cada professor alfabetizador, com apoio e autorização do Secretário da Educação e da equipe técnica. A escolha desse município se deu em razão do envolvimento das pesquisadoras com a formação continuada dos professores alfabetizadores nos últimos três anos.

O roteiro foi organizado utilizando como referência as questões discutidas por Marcelo (1999) sobre o desenvolvimento profissional dos professores, contendo questões que possibilitaram uma caracterização geral do grupo (tempo de atuação no magistério, em turmas de alfabetização, formação inicial e continuada) e demais perguntas relacionadas ao objeto de estudo proposto sobre desenvolvimento profissional. 
No processo de análise, as questões foram organizadas em quatro categorias na perspectiva de acontecimentos "charneira" (JOSSO, 2004): caracterização do grupo participante; escolha pelas turmas de alfabetização; início na carreira; aprendizagens e expectativas como professor alfabetizador. Os dados foram inicialmente organizados, analisados no conjunto de cada questão, expressando os resultados em subcategorias, considerando as etapas de análise de conteúdo conforme Bardin (2007).

Os sujeitos participantes desta pesquisa são professores alfabetizadores atuantes em turmas do primeiro ao terceiro anos do Ensino Fundamental, sendo quatorze do gênero feminino e três do masculino e atuam em turmas de alfabetização nos períodos manhã e tarde, sendo 11 professores no primeiro ano, 2 no segundo ano e 4 no terceiro ano do ensino fundamental. Os dados referentes ao tempo no magistério e o tempo de atuação em turmas de alfabetização foram organizados em tabela 1, a seguir:

Tabela 1 - Tempo de atuação no magistério municipal e na alfabetização

\begin{tabular}{|lcccc}
\hline \multicolumn{1}{|c|}{$\begin{array}{c}\text { Número de } \\
\text { atuação }\end{array}$} & $\begin{array}{c}\text { Número de } \\
\text { professores por } \\
\text { ano de atuação } \\
\text { no magistério } \\
\text { municipal }\end{array}$ & $\begin{array}{c}\text { porcentagem } \\
\text { ano de atuação } \\
\text { em turmas de } \\
\text { alfabetização }\end{array}$ & $\begin{array}{c}\text { Porcentagem } \\
\text { de tempo de } \\
\text { atuação em } \\
\text { alfabetização }\end{array}$ & $\begin{array}{c}\text { de tempo de atu- } \\
\text { ação profissional } \\
1 \text { a 25 anos }\end{array}$ \\
\hline 1 a 5 anos & 2 & 5 & $29,5 \%$ & $11,5 \%$ \\
\hline 6 a 10 anos & 3 & 3 & $17,5 \%$ & $17,5 \%$ \\
\hline 11 a 15 anos & 6 & 5 & $29,5 \%$ & $35,5 \%$ \\
\hline 16 a 20 anos & 3 & 2 & $11,5 \%$ & $17,5 \%$ \\
\hline 21 a 25 anos & 3 & 2 & $11,5 \%$ & $17,5 \%$ \\
\hline Total & 17 & 17 & $100 \% *$ & $100 \% *$ \\
\hline
\end{tabular}

Fonte: Dados de investigação.

Nota: *Por arredondamento. 
Os dados sobre tempo de atuação no magistério e em turmas de alfabetização expressam que a maioria (88\%) das professoras participantes são experientes com cinco anos ou mais de atuação, poucas iniciantes (11,5\%) no magistério municipal. Sobre atuação na alfabetização, os dados indicam um percentual maior $(29,5 \%)$ de professores alfabetizadores iniciantes, mas a maioria (70,5\%) já atua como alfabetizador por mais de cinco anos. Esses dados apontam para uma amostra válida ao estudo de desenvolvimento profissional, pois é possível analisar suas aprendizagens e experiências com a alfabetização há mais de cinco anos.

Assim, o marco de início do desenvolvimento profissional decorre da escolha do curso, em que a maioria dos professores possui formação de nível superior específica para atuar nos anos iniciais do ensino fundamental (Pedagogia e Normal Superior), poucos têm formação de nível médio mais específica para o nível em que atuam e, apenas uma é licenciada em História. $\mathrm{O}$ exame das aprendizagens poderá contribuir para a compreensão dos elementos do desenvolvimento profissional apresentado a seguir.

\section{Desenvolvimento profissional dos professores alfabetizadores: os momentos e espaços de sua composição}

No estudo realizado, a análise dos dados apontou como categorias centrais do desenvolvimento profissional: o tempo, o espaço e os conhecimentos profissionais. O tempo entendido em sua extensão, marcado por momentos "charneira”, isto é, momentos marcantes, pois, no exercício do magistério, possibilita aos professores a experiência prática.

A experiência favorece a apropriação de conhecimentos relacionados ao ensinar, ao estabelecimento de rotinas em sala de aula, e organização de conhecimentos advindos das formações. Além disso, permite o desenvolvimento da segurança emocional diante da resolução de problemas pedagógicos e de relacionamento, o domínio dos aspectos 
metodológicos e de conteúdos específicos do currículo, e aprendizagens direcionadas ao desenvolvimento profissional.

Os participantes do estudo apontam como momentos marcantes no seu desenvolvimento profissional: a) a inserção profissional. Um segundo grupo refere-se a tempo e espaço: b) a formação durante a prática pedagógica; c) a formação continuada. E um grupo de elementos, direciona-se ao espaço: d) as condições de trabalho.

No caso específico de professores alfabetizadores, na composição do desenvolvimento profissional, os conhecimentos destacados abrangem: o processo de apropriação da escrita pela criança e a metodologia que viabiliza o trabalho em sala de aula, a compreensão do processo de aprendizagem e os pressupostos do ciclo de alfabetização. Já na prática pedagógica, a possibilidade de favorecer a apropriação e consolidação do sistema de escrita alfabética, assim como saber trabalhar com possíveis intervenções na aprendizagem das crianças, são os resultados apontados pelas análises do estudo realizado. Esses conhecimentos se apresentam intrinsecamente articulados ao tempo e espaço.

a) A inserção profissional como momento marcante no desenvolvimento profissional. Ressaltamos que a inserção profissional para muitos professores é um momento determinante para os anos que se seguem. É um período em que, segundo Marcelo (2009), os elementos da docência (conhecimentos, valores, símbolos), são transmitidos aos professores iniciantes. Na investigação realizada com os professores alfabetizadores, $80 \%$ deles declaram que tiveram muitas dificuldades, devido à falta de experiência com a alfabetização, falta de conhecimentos pedagógicos, insegurança. Os professores relatam da seguinte maneira, a título de exemplo:

Tudo novo, muitas vezes um pouco de medo, pois se tratava de ensinar aqueles olhos curiosos dos pequenos olhando para mim. Pois tinha muito que aprender porque faltava em mim mais experiência (P1); Era uma professora com pouco conhecimento pedagógico, poucas experiências nas práticas educativas, mas com muita vontade e desejo de crescer (P8). 
Os relatos dos professores alfabetizadores levantam questões ligadas ao processo de inserção profissional, que deveria receber mais atenção dos gestores escolares na perspectiva de apoio profissional técnico e de colegas, como destaca Marcelo (1999).

O apoio profissional técnico ao professor ocorre por meio dos cursos de formação, que deveriam ser planejados considerando a inserção desse professor nas turmas de alfabetização, abordando as práticas alfabetizadoras e auxiliando os professores a transferirem os conhecimentos aprendidos em suas classes. Isto demanda encontros frequentes e pautados em situações de sala de aula, as expectativas dos professores em relação à prática e ao aprendizado de professor alfabetizador.

O apoio profissional entre colegas pressupõe a promoção do diálogo e a reflexão sobre o ensino: designar um professor experiente, que pudesse ser observado em sua ação e observar os colegas, para realizar uma análise das práticas e do processo de aprendizagem. Esse tipo de apoio impacta positivamente o desenvolvimento profissional dos professores e vem a estabelecer um ambiente de cooperação nas escolas, como explica Marcelo (1999).

b) A formação durante a prática pedagógica pela possibilidade de acompanhar o processo inicial de apropriação da escrita e da leitura pelas crianças: elemento do desenvolvimento profissional relaciona-se ao tempo e espaço da prática profissional, pois propicia aos professores aprendizagem de conhecimentos que viabilizam o acompanhamento da apropriação da escrita e da leitura pelas crianças.

De modo geral, esses conhecimentos estão relacionados ao movimento que teve início na década de 80, quando os estudos da psicogênese da língua escrita chegaram ao Brasil. Esse movimento ocasionou uma revolução conceitual, termo utilizado por Mortatti (2000), devido às discussões trazidas pelos especialistas das universidades e centros de pesquisas com enormes repercussões na atuação profissional de professores alfabetizadores.

Os professores alfabetizadores se referem ao aprendizado destes conhecimentos como fundamentais para sua atuação profissional. 
Algumas tiveram acesso a eles (conhecimentos) em cursos de formação continuada, outras em conversas e reuniões na escola e outras já possuíam a partir de seus cursos de formação inicial. Encontramos no relato dos professores:

A cada ano que passa eu me sinto mais preparada, sempre buscando mais. $O$ PNAIC veio para ajudar e muito, com troca de experiências importantes para mim (P4); Aprendi várias coisas com os cursos que fiz pela secretaria de educação, e quero continuar atuando como professor alfabetizador (P5).

Para Soares (2004), o período foi marcado por uma mudança paradigmática sobre a concepção de aprendizagem da escrita expresso pela teoria cognitivista. A autora destaca que no contexto deste novo paradigma produziram-se falsas inferências que levaram a equívocos no processo de ensino. Um desses equívocos foi a compreensão de que apenas por meio do intenso convívio com o material escrito seria suficiente para a criança se alfabetizar. Isso levou a uma secundarização do papel do professor e da necessidade de métodos de ensino.

Isso provocou um movimento de mudança na prática alfabetizadora e instituiu a necessidade de uma formação relacionada: "[...] ao conhecimento dos processos de aprendizagem das crianças, visando a conciliação entre a competência técnica e o compromisso político necessários para a construção da qualidade de ensino na escola democrática" (Mortatti, 2000, p. 254).

Em pesquisa realizada por Cartaxo (2009) identifica-se uma mudança significativa no conteúdo dos cursos de formação para o alfabetizador: do treinamento em métodos de alfabetização para discussões e reflexões sobre a alfabetização. Este período coincide com o que Martins (1998) denominou de "Dimensão política do ato pedagógico", marcado por intensa participação social e seguido de um segundo momento "A organização do trabalho na escola", com novas formas de organização da escola e de formação dos professores. 
Além da formação pela experiência, as respostas dos professores participantes do estudo indicam suas expectativas em relação à prática, como relacionadas ao desenvolvimento profissional em duas possibilidades: expectativa em relação aos resultados do trabalho direcionados à aprendizagem da leitura e da escrita pelos alunos e expectativa quanto à sua prática para possibilitar melhoria das atividades desenvolvidas para os alunos.

Em relação aos resultados do trabalho, os professores P3 e P6, atuantes em escolas diferentes nesse município, registraram que: "Minhas expectativas são em ver os resultados do meu trabalho" (P3); "Cada ano minhas expectativas aumentam em relação aos resultados do trabalho, ver todos lendo e escrevendo" (P6).

A expectativa sobre os resultados do trabalho do professor alfabetizador tem relação com o processo de alfabetização, considerando que as crianças, ao final do terceiro ano, deverão ter desenvolvido determinadas competências e habilidades de leitura e escrita. Neste sentido, os depoimentos contêm esse elemento, ou seja, o desenvolvimento profissional do professor alfabetizador assume a aquisição da leitura e da escrita, isto é a aprendizagem dos alunos conforme Day (2001). Além disso, a intensa aprendizagem na prática docente constitui-se em conhecimentos basilares do desenvolvimento profissional.

No que se refere a melhoria das atividades desenvolvidas para os alunos, entre os depoimentos uma professora respondeu que sua expectativa estava em: "Ser um professor inovador criativo nas minhas aulas sempre procurando aperfeiçoar meu conhecimento nesta área e dar o melhor de mim" (P13). Os professores demonstram preocupação com o trabalho e a aprendizagem dos alunos, o que se estabelece, segundo Martins (2008), como um dos dilemas do processo de ensino.

Ao se depararem com problemas na aprendizagem dos alunos, a primeira ação é a modificação de técnicas e estratégias de ensino, colocando nas aulas uma série de atividades que, muitas vezes, são mais resultados de respostas às situações da prática que vão se transformando em experiências. Essas experiências passam a compor os saberes que advém da prática se relatadas em reuniões, diários de trabalho, discussões, 
cotejamentos com leituras, possibilitando estudos e sistematizações, integrando aprendizagens que se agregam ao desenvolvimento profissional dos professores.

c) A formação continuada: um dos elementos presentes no desenvolvimento profissional se expressa por meio de aprendizagens realizadas nos processos de formação continuada, tanto no momento de inserção profissional como ao longo da carreira. Os professores alfabetizadores do estudo afirmaram que participam da Semana de Estudos Pedagógicos, uma modalidade de formação realizada uma vez ao ano. Essa formação é planejada pela equipe técnica da Secretaria de Educação e consiste em oficinas e palestras com temas diversos, que buscam atualizar os conhecimentos dos docentes, rever metodologias, rediscutir a prática e buscar melhorias na qualidade do ensino. Os temas abordados, segundo dados da pesquisa, são sugeridos pelos professores e escolhidos a partir do levantamento da equipe da secretaria. Os professores alfabetizadores relatam:

Participo da Semana de Estudos que o pessoal da Secretaria organiza, nos últimos anos trouxeram bons professores (P8); As minhas necessidades são sempre buscar mais e mais conhecimento e os estudos na Semana Pedagógica me ajudaram muito (P16).

Outro dado apontado pela pesquisa é a participação de $60 \%$ dos professores na formação presencial, realizada a partir do Pacto Nacional pela Alfabetização na Idade Certa (PNAIC). O PNAIC é uma ação do Ministério da Educação que integra o Governo Federal, Estados e Municípios, oficializada em 2012, com o propósito de garantir que as crianças até oito anos de idade alcancem a alfabetização plena. Para isso, foram desenvolvidos programas, materiais e referenciais curriculares e pedagógicos voltados à formação dos professores alfabetizadores. O programa de formação é organizado por Instituições de Ensino Superior, definidas pelo Ministério da Educação, que prepararam os orientadores de estudos das próprias redes de ensino para conduzir as atividades de formação com os grupos de professores alfabetizadores. 
Os professores alfabetizadores pesquisados participaram das formações com carga horária de aproximadamente 120 horas ao longo de um ano letivo, organizadas com material de leitura, vídeos, sequências didáticas para aplicação em sala de aula e análise. Pelas características dessa ação proposta nacionalmente, os professores municipais foram indicados a participar das formações do PNAIC no município, como demonstram os seguintes relatos:

Fui chamada pela diretora para fazer o curso do PNAIC, no começo não queria, mas hoje utilizo os livros do pacto principalmente a unidade 03 (P14); As professoras da Secretaria me chamaram para informar que faria o curso do PNAIC, uso tudo, tudo. Muito bom (P16).

Mesmo com a oferta de cursos, alguns depoimentos indicam que solicitam mais oportunidades, como por exemplo "Falta de oportunidade para novos conhecimentos (cursos)" (P12). Portanto, há compreensão de que os cursos podem ser uma forma de melhoria do desenvolvimento profissional.

Neste sentido, o estudo confirma as proposições de Day (2001), as quais destacam que cursos de formação têm como objetivo a aprendizagem intensiva, em um curto período, planejada em conjunto. Essa é apenas uma das possibilidades de investimento no desenvolvimento profissional, já que o autor ainda discute que atividades de formação consideradas bem-sucedidas são planejadas, atendendo necessidades-alvo, necessidades de conteúdo, necessidades de utilização e necessidades processuais.

d) As condições de trabalho envolvem necessidades e expectativas. Entre as necessidades, pode-se citar, por exemplo, a da escola ao precisar de professores para atuar em turma de alfabetização. Um grupo de investigadas referem-se à inserção como alfabetizadoras por condições de trabalho, outro grupo aponta a turma disponível na escola. Logo, uma escolha em ser alfabetizadora condicionada pelo espaço, e, em alguns casos, imposta. No entanto, esse grupo de professoras permanece atuando 
como alfabetizadoras, algumas ao longo de sua carreira. No caso da escolha, há indicação de atitude de cooperação do professor em relação à escola, no sentido de colaborar com a organização. Os depoimentos a seguir exemplificam esta situação.

Um dos professores participantes da pesquisa relatou que começou na turma de alfabetização da seguinte maneira: "Na época foi a necessidade da escola e comecei a ter o gosto de ensinar a ler e escrever" (P14). Outro professor apresentou a seguinte justificativa: "No início foi pela necessidade, poucas horas. Pela localização, pois escola é do lado de casa" (P11).

Segundo Gonçalves (1995), os professores apresentam no decorrer da trajetória profissional três processos em desenvolvimento:

Processo de crescimento individual, em termos de capacidade, personalidade e capacidade pessoal de interação com o meio; processo de aquisição e aperfeiçoamento de competências de eficácia no ensino e de organização do processo ensino-aprendizagem; e processo de socialização profissional, em termos normativos ou de adaptação ao grupo profissional a que pertence e à escola onde trabalha [...] (GONÇALVES, 1995, p. 147).

No grupo pesquisado, as questões relacionadas à socialização parecem ter influenciado na escolha, quando a necessidade da escola é atendida pelo professor. De acordo com Gonçalves (1995), motivos sociopolíticos, culturais e econômicos influenciam a tomada de decisão dos professores em relação ao contexto da escola em que desempenham suas atividades, como foi possível identificar na pesquisa.

No que concerne às condições de trabalho, o estudo aponta a indicação de expectativas pertinentes a sua melhoria, expressas como necessidades, tais como: material didático e pedagógico e apoio da equipe e comunidade escolar. Conforme colocações de professores participantes:

Falta de livros didáticos para todos os alunos, a carência no material pedagógico e ajuda dos pais (P2); Falta de material pedagógico e ter mais apoio dos pais (P8); Tenho necessidades de materiais pedagógicos e mais participação dos pais na vida escolar dos filhos (P9). 
Quanto ao material didático e pedagógico, especificamente em relação a material didático de alfabetização, o Brasil tem o Programa Nacional do Livro Didático (PNLD), que distribui livros didáticos às escolas públicas. Os livros são escolhidos pelos professores em ciclos trienais, com reposição dos materiais a cada ano para os alunos de primeiro ano do Ensino Fundamental. O número de exemplares distribuídos é organizado a partir do censo escolar do ano anterior ao ano escolar vigente, o que pode explicar a dificuldade dos professores em terem o material para todos os alunos em determinadas épocas do ano. No entanto, os professores investigados estão indicando outros materiais que poderiam contribuir com a prática docente do professor alfabetizador.

E em relação ao apoio da equipe escolar e da comunidade escolar, tanto o apoio da gestão escolar como da participação da família na escola é fundamental, ou seja, o desenvolvimento profissional dos professores é processo coletivo, em que as condições do espaço escolar estão diretamente relacionadas. Para tanto, os professores e gestores ao discutirem o que necessitam das famílias e como podem proceder as orientações, de forma que os pais entendam o posicionamento da escola, podem contribuir com o desenvolvimento profissional dos docentes.

Nesse cenário, nos deparamos com elementos que envolvem políticas públicas para a educação e planejamento de gestores públicos, para que aconteça a aquisição de materiais pedagógicos e promoção da formação continuada.

Portanto, ao avaliar as necessidades e expectativas para a melhoria de sua atuação profissional, os professores decorrem reflexões que contribuem com o desenvolvimento profissional. Sobre as necessidades de conhecimentos necessários ao desempenho profissional, no caso da alfabetização, podem-se elencar os conteúdos relacionados ao sistema de leitura e escrita alfabético. Muitos professores julgam saber sobre este processo, mas repensarem sobre suas necessidades e expectativas configura-se um espaço para retomar esses conhecimentos.

Os elementos que caracterizam o desenvolvimento profissional e os professores alfabetizadores, definidos ainda em caráter provisório neste 
estudo, envolvem acontecimentos "charneira", ou seja, momentos especiais da inserção e atuação profissional numa composição das aprendizagens realizadas pelas incertezas do ingresso, as aprendizagens realizadas nos cursos de formação continuada, as aprendizagens na prática advindas da organização da prática pedagógica para obtenção dos resultados da aprendizagem dos alunos e nas reflexões sobre as condições de trabalho que se expressam por meio das necessidades como expectativas para a melhoria desta condição. Enfim, o estudo possibilitou uma introdução à compreensão do desenvolvimento profissional do professor alfabetizador.

\section{Considerações finais}

O estudo realizado conseguiu indicar algumas respostas sobre quais seriam os momentos, espaços e elementos constitutivos do processo de desenvolvimento profissional de professores alfabetizadores a partir da análise dos depoimentos dos professores. Ao compreender o desenvolvimento profissional de professores alfabetizadores, tomando como ponto de partida o tempo e o espaço em que os acontecimentos e aprendizagens ao longo da carreira se constituem como elementos basilares desse desenvolvimento, procuramos ir além do factual, o que implica procurar a compreensão do que representa o tornar-se professor alfabetizador.

A primeira consideração é a de que o desenvolvimento profissional do alfabetizador mantém tempos e espaços semelhantes aos demais professores, no entanto se diferencia quanto aos conhecimentos e a forma. As semelhanças se expressam quanto aos momentos "charneiras" (JOSSO, 2004; MARCELO, 2009), tais como a inserção profissional, e quanto ao espaço da formação na escola e na formação continuada. Todavia, a forma expressa peculiaridades considerando a imediatez dos resultados do processo de aprendizagem dos alunos, pois a aprendizagem da leitura e da escrita se apresenta "visível" aos professores em pouco tempo.

Igualmente, os resultados da pesquisa demonstraram um tempo de atuação no magistério e em turmas de alfabetização muito próximos 
e em contínuo, o que permite considerar que há uma permanência dos professores alfabetizadores no exercício profissional. Com efeito, devido a um número elevado de professoras alfabetizadoras iniciantes, verifica-se que são destinados à alfabetização professores recém ingressos na profissão e na escola. Entretanto, após essa inserção muitas professoras permanecem como alfabetizadoras. Esse é um elemento fundamental visto que esse tempo promove o domínio sucessivo dos saberes para a realização do trabalho, condição de promoção do desenvolvimento profissional. Pesquisas específicas com professores de outros segmentos da educação básica podem vir a confirmar se esta é uma peculiaridade específica do professor alfabetizador.

Quanto à escolha pelas turmas de alfabetização incidir ao professor iniciante para acompanhar a apropriação da escrita pelas crianças, uma possível hipótese pode estar correlacionada ao processo de formação inicial desses professores, pois, de modo geral, os currículos dos cursos incluem conhecimentos relativos ao desenvolvimento da aprendizagem das crianças e ao processo de aquisição da leitura e da escrita. Com efeito, os conhecimentos adquiridos durante a formação inicial proporcionam ao professor certa segurança, impelindo a escolha de classes escolares referentes aos três primeiros anos do ensino fundamental por considerar que possui domínio do processo de alfabetização. Novos estudos são necessários para aprofundar essa questão.

O início de carreira foi considerado pelos professores como um momento de dificuldade e insegurança em relação à prática nas turmas de alfabetização, porém, por outro lado, tais turmas favorecem a perspectiva de obtenção de resultados em tempo menor que em outros segmentos da educação básica. Os professores demonstraram que suas expectativas estão direcionadas a aprendizagem da leitura e escrita pelos alunos, a partir de atividades atrativas.

Quanto à insegurança sobre propostas de acompanhamento e apoio aos professores iniciantes, com trabalhos de supervisão técnica individuais, organização de grupos de estudo, apoio de colegas na 
observação de aulas e feedback formativo, reafirma-se a necessidade de programas específicos direcionados aos professores iniciantes.

É possível partilhar, neste momento, que o desenvolvimento profissional dos professores alfabetizadores está marcado pela inserção em turmas de alfabetização desde o início da carreira, por contar com o apoio das equipes escolares e formação continuada. Ressaltamos, contudo, que os professores alfabetizadores consideram a formação realizada a partir de sua prática como fundamental para proporcionar sentido à sua profissão. A prática é poderosa na composição do desenvolvimento profissional, não por si só, mas por permitir constituir-se em experiências profissionais que, refletidas, estão na base dos saberes docentes sobre a alfabetização.

As condições para o trabalho docente são marcantes no desenvolvimento profissional dos professores, uma vez que buscam atender as necessidades da instituição e suas próprias necessidades. De outra perspectiva, contraditoriamente, isso pode estabelecer uma acomodação para evitar o enfrentamento com a gestão escolar.

Quanto ao programa de ações de formação continuada promovido pelo Pacto Nacional pela Alfabetização na Idade Certa (PNAIC), pode-se afirmar que os professores os consideram relevante, porém insuficiente. Há solicitações da expansão de propostas formativas, o que pode indicar que os professores reivindicam se tornar especialistas em alfabetização e não meros executores de atividades de leitura e escrita.

Especificamente, a produção de materiais e a composição de acervos de leituras para professores alfabetizadores e alunos em alfabetização, se constitui em uma necessidade do processo formativo, nem sempre atendida, como assinalam os dados da pesquisa. Além disso, cabe enfatizar que a leitura do professor é essencial para o professor alfabetizador. Nesse sentido, é fundamental mudar a compreensão histórica sobre a alfabetização no Brasil, superando a concepção da alfabetização como um mero processo de codificação e decodificação.

Retomando os aportes teóricos deste estudo sobre desenvolvimento profissional dos professores, com a expectativa de compreender e ampliar o debate sobre o processo de profissionalização docente, algumas 
problemáticas podem ser apresentadas. O estímulo para a proposição da profissionalização docente é orientado para a melhoria do exercício profissional, e ao assumir este rumo não estaria limitando o aprendizado do professorado apenas a técnicas de intervenção na prática para a obtenção de resultados imediatos nos processos de avaliação dos sistemas educacionais? Portanto, a finalidade da formação continuada é possibilitar conhecimentos diretamente vinculados à prática de ensino para melhor desempenho refletido numa pedagogia de resultados? O estudo realizado trouxe consideráveis elementos que permitiram examinar o desenvolvimento profissional do alfabetizador sob esta ótica, contudo, devido ao limite de sujeitos e espaço pesquisados, há exigência de novas investigações.

Finalmente, enfatizamos que o estudo realizado reforça a necessidade dos conhecimentos sobre o processo de desenvolvimento da cognição em relação a leitura e a escrita e do próprio processo de alfabetização (teoria e prática) estarem presentes nos cursos de formação inicial, bem como instituir a existência de programas de apoio aos professores iniciantes e promover a continuidade de programas de formação continuada, focalizando a alfabetização e a valorização dos alfabetizadores, de modo a reconhecer esta especialidade na composição da profissão docente.

\section{Referências}

BARDIN, L. Análise de conteúdo. Lisboa: Edições 70, 2007.

BOGDAN, R. C.; BIKLEN, S. K. Investigação qualitativa em educação: uma introdução à teoria e aos métodos. Porto: Porto Editora, 1994.

CAMPBELL, A. Teachers' research and professional development in England: some questions, issues and concerns. Journal of In-Service Education, v. 29, n. 3, p. 375-388, set. 2007. Disponível em: <http://www.tandfonline.com/doi/ pdf/10.1080/13674580300200281>. Acesso em: 20 set. 2016. 
CANÁRIO, R. Formação e desenvolvimento profissional dos professores. In: CONFERÊNCIA DESENVOLVIMENTO PROFISSIONAL DE PROFESSORES PARA A QUALIDADE E PARA A EQUIDADE DA APRENDIZAGEM AO LONGO DA VIDA, 2007, Lisboa. Anais... Lisboa: Ministério da Educação/Direção-Geral dos Recursos Humanos da Educação, 2007. p. 133-148.

CARTAXO, S. R. M. Formação continuada do professor alfabetizador: abordagens, processos e práticas. 2009. 149 f. Dissertação (Mestrado em Educação) Pontifícia Universidade Católica do Paraná, Curitiba, 2009.

COSTA, M. R. Avaliação do desempenho docente no ensino médio: caminho para o desenvolvimento profissional? Contrapontos, v. 7, n. 1, p. 107-127, jan./abr. 2007. Disponível em: <http://educa.fcc.org.br/scielo.php?script=sci_arttext\&pid=S1984-71142007000100008\&lng=pt\&nrm=iso >. Acesso em: 09 out. 2016.

DAY, C. Desenvolvimento profissional de professores: os desafios da aprendizagem permanente. Porto: Porto Editora, 2001.

DESIMONE, L. M. Improving impact studies of teachers' professional development: toward better conceptualizations and measures. Educational Researcher, v. 38, n. 3, p. 181-199, abr. 2009.

GONÇALVES, J. A. M. A carreira das professoras do ensino primário. In: NÓVOA, A. (Org.). Vidas de professores. Porto: Porto Editora, 1995. p. 141-169.

GONTIJO, C. M. M. A escrita infantil. São Paulo: Cortez, 2008.

GONTIJO, C. M. M. Alfabetização: políticas mundiais e movimentos nacionais. Campinas: Editora Autores Associados, 2014.

HUBERMAN, M. O ciclo de vida profissional dos professores. In: NÓVOA, A. (Org.). Vidas de professores. Porto: Porto Editora, 1995. p. 31-61.

JOSSO, M. C. Experiências de vida e formação. São Paulo: Cortez, 2004.

KLEIMAN, A. B. Modelos de letramento e as práticas de alfabetização na escola. In: KLEIMAN, A. (Org.). Os significados do letramento: uma nova perspectiva sobre a prática social da escrita. Campinas: Mercado de Letras, 1995. p. 15-61. 
MARCELO, C. Formação de professores: para uma mudança educativa. Porto: Porto Editora, 1999.

MARCELO, C. Desenvolvimento profissional docente: passado e futuro. Sísifo. Revista de Ciências da Educação, n. 8, p. 7-22, jan./abr. 2009.

MARTINS, P. L. O. A didática e as contradições da prática. Campinas: Papirus, 1998.

MARTINS, P. L. O. O campo da Didática: expressão das contradições da prática. In: EGGERT, E.; TRAVERSINI, C.; PERES, E.; BONIN, I. (Orgs.). Trajetórias e processos de ensinar e aprender: didática e formação de professores. 1. ed. Porto Alegre: EDIPUCRS, 2008. p. 585-601.

MORTATTI, M. R. L. Os sentidos da alfabetização. São Paulo: Unesp, 2000.

ROMANOWSKI, J. P.; MARTINS, P. L. O. Formação continuada: contribuições para o desenvolvimento profissional dos professores. Revista Diálogo Educacional, v. 10, n. 30, p. 285-300, 2010.

SOARES, M. Letramento: um tema em três gêneros. Belo Horizonte: Ceale/ Autêntica, 1998.

SOARES, M. Letramento e escolarização. In: RIBEIRO, V. M. (Org.). Letramento no Brasil: reflexões a partir do INAF. São Paulo: Global, 2004. p. 89-113.

TARDIF, M. Saberes docentes e formação profissional. Petrópolis: Vozes, 2010.

VAILLANT, D.; MARCELO GARCIA, C. Ensinado a ensinar: as quatro etapas de uma aprendizagem. Curitiba: Ed. UTFPR, 2012.

Recebido: 20/10/2016

Received: 10/20/2016

Aprovado: 20/11/2016

Approved: 11/20/2016 